\title{
Lateral asymmetry in the perceived sequence of speech and nonspeech stimuli*
}

\author{
PAUL BERTELSON and FRANÇOISE TISSEYRE† \\ University of Brussels, Brussels, Belgium
}

The task was to estimate the position where a click had been superimposed in a spoken sentence. Experiment 1 confirmed Fodor and Bever's observation of an ear-asymmetry effect: the click is located earlier when it is presented to the left ear and the sentence to the right ear than with the opposite arrangement. In Experiment 2, combinations of monaural and binaural presentations were considered. They made it possible to eliminate interpretations which link the laterality effect to the fact of reaching or not reaching a particular ear and showed that the relevant factor is the relative position of the stimuli in acoustic space. Experiments 3 and 4 explored the relation between spatial separation and perceived sequence in greater detail. The relation involves a plateau: when the click comes to the left of the speech, it is preposed to a degree which depends on the amount of spatial separation; but, when it comes to the right of the speech, separation is irrelevant and the mean error is of the same order of magnitude as in a control condition without separation.

The present study was stimulated by an observation reported by Fodor and Bever (1965) in the well-known paper where they analyzed the influence of grammatical structure on the apparent location of an extraneous signal in a spoken sentence. Contrary to Ladefoged and Broadbent (1960), who had used diotic presentations through loudspeakers in open space, Fodor and Bever used dichotic presentations through earphones, the speech being delivered to one ear and the signal (a click) to the other ear. They mentioned among their accessory results that negative displacements (i.e., locating the signal earlier than its objective position) prevailed for the Ss who heard the signal in the left ear and the speech in the right ear and positive displacements for those who had the opposite arrangement. This remarkable finding has been confirmed in further experiments by Bever and his associates (Bever, Lackner, \& Stolz, 1969; Bever, Lackner, \& Kirk, 1969). It has, however, not been subjected to a systematic experimental analysis and, as a result, has gone somewhat

*This work was carried out under Contract 612 between the Belgian "Fonds de la Recherche fondamentale collective," the University of Brussels, P. Bertelson (Laboratoire de Psychologie expérimentale), and $M$. Waiskop (Institut de Phonétique). Help was received from the "Institut de Phonétique" at all stages: Monique Wajskop-Hianne constructed and recorded the sentences; $A$. Landercy developed the procedure for positioning the clicks, designed the voice key, and calibrated the clicks and the sentences; and $M$. Wajskop made the remarkable facilities of his laboratory available.

tRequests for reprints should be sent to: P. Bertelson, Laboratoire de Psychologie expérimentale, 117 avenue Ad. Buyl, 1050 Bruxelles, Relgium. unnoticed, ${ }^{1}$ despite the wide interest which has developed recently for laterality effects in dichotic listening (Kimura, 1961, 1964) and in tachistoscopic recognition (see the review by White, 1969). The following experiments were run to analyze the phenomenon further.

\section{MATERIAL AND APPARATUS}

The material was the same as in a previous study by the authors (Bertelson \& Tisseyre, 1970). Briefly, it consisted of French sentences, 11 to 15 syllables long (mean: 13.6), recorded at a very fast pace ( 7 syllables/sec) by a female speaker. There were four lists of 10 sentences each, matched for intonation pattern. The sentences were recorded on one track of the tape, and 1-msec signals were positioned on the other track, at locations always corresponding to the middle of a vowel. Positions ranging from the 4th to the 12th syllable of the sentence were used, with roughly equal probabilities. The mean position was 0.4 syllable after the middle of the sentence.

A set of Sharpe HA-8 padded earphones was used for delivering the material to the So. Each earphone was connected to one output channel of a stereophonic amplifier (MBLE Type 660/845). The tapes were played on a Revox A77 tape recorder. The output of the signal track was connected to a voice key (Landercy, 1970) which, when activated, produced a 1-msec rectangular pulse of adjustable amplitude. This was fed either to one or to both low-level inputs of the amplifier, while the output from the other track of the tape recorder was similarly connected to the high-level inputs. The sentence and the click could thus each be sent to one particular ear or to both ears, making all combinations of monaural and binaural presentations possible.

The loudness levels of the sentences and of the click were measured using an artificial ear (Brüel \& Kjaer, Type 4152) with a 6-cc coupler, a Brüel \& Kjaer 2603 microphone amplifier, and a Hewlett-Packard Loudness Analyzer, Model $8501 \mathrm{~A}$. The peak loudness levels for the sentences ranged from 25 to 35 sones. The clicks used in Experiments 2, 3, and 4 were 35 sones. Those of Experiment 1 were 35 (weak) and 55 (strong) sones.

\section{EXPERIMENT 1}

The main purpose of this experiment was to replicate Fodor and Bever's observation of an ear-asymmetry effect. The two presentation modes used by the authors, i.e., sentence right/click left and sentence left/click right, were compared. Simultaneously, the possible role of the intensity of the click was analyzed. This was an important precaution for the combinations of monaural and binaural presentations which were planned for later experiments.

\section{Method}

Four conditions were compared, resulting from the combination of two presentation modes $-S_{R} C_{L}$ (sentence to right ear, click to left ear) and $S_{L} C_{R}$ (opposite arrangement)-and of two loudness levels for the click-strong (55 sones) and weak (35 sones). The latter was equal to the peak level of the loudest sentences. Each $S$ had one list of 10 sentences under each of the four conditions. Half the Ss started with the two conditions with the strong click, half with the weak click. Within each group, the order of the two presentation modes was similarly balanced. Four Ss were tested under each of the four resulting orders, and the order of the four lists was organized in Latin square among them.

The $16 \mathrm{Ss}$ were students and were paid for their participation.

They were told that a click would be heard during each sentence, that it could occur in any position, and that their task was to report their best estimation. They wrote down the passage around the place where they thought the click had occurred, with a vertical bar indicating that position.

Errors were scored in number of intersyllable intervals separating the position which was reported from the position on which the click actually occurred, a half unit being counted when the reported position fell exactly in the interval between two syllables. They were called negative when the 
reported position preceded the actual position. If, e.g., the bar on the S's protocol fell on any of the letters of the syllable following the actual position, an error of +1 syllable was counted. If it fell between the two syllables, the score was +0.5 syllable. In our previous study (Bertelson \& Tisseyre, 1970), the Ss were told that the click was always superimposed on vowels, and so no provision had to be made for responses falling between syllables. It was decided not to provide that information any longer for fear that it might reduce the sensitivity of the responses, and the scoring system had to be adjusted accordingly.

The Ss had no prior knowledge of the sentences which were presented only once, with the click. Before each list began, the way in which the material would be distributed between the ears was explained.

\section{Results and Discussion}

In Table 1 , the responses have been broken down into the three categories of negative errors, correct responses, and positive errors. At both click intensities, there are more negative errors and less positive ones in Condition $S_{R} C_{L}$ than in $S_{L} C_{R}$. The proportion of correct responses is little iffected. On the other hand, the breakdown is really not influenced by the intensity of the click, except for a very slightly larger proportion of correct responses with the strong click.

The same general pattern appears in mean errors, also shown in Table 1 , which are not affected by click intensity but are very strongly affected by presentation mode. Analysis of variance showed a significant effect of presentation mode $(F=15.1$, $\mathrm{df}=1,15, p<.01$ ) and no effect of click intensity $(F<1)$.

The apparent temporal position of the click is clearly affected by the way the two components of the task are allotted to the two ears. Fodor and Bever's ear-asymmetry effect has thus been confirmed.

On the other hand, the results differ from Fodor and Bever's in that a strong tendency towards negative displacement is observed under both presentation modes. Even in Condition $S_{L} C_{R}$, where the tendency is less pronounced, $68 \%$ of erroneous responses are on the negative side (against $43 \%$ in Fodor and Bever's experiment) and the mean error is negative in 12 of the $16 \mathrm{Ss}(p=.08 \mathrm{by}$ a sign test) and for 36 of the 40 sentences. The problem will be considered again in the general discussion.

\section{EXPERIMENT 2}

The nature of the ear-asymmetry effect as demonstrated by Fodor and Bever and confirmed in Experiment 1

Table 1

Reaults of Experiment 1

\begin{tabular}{|c|c|c|c|c|c|c|}
\hline \multicolumn{2}{|c|}{ Condition } & \multirow{3}{*}{$\begin{array}{c}\text { Mean } \\
\text { Error*+ }\end{array}$} & \multirow[b]{3}{*}{$\mathbf{S D}^{*}$} & \multirow{2}{*}{\multicolumn{3}{|c|}{ Percent Errorst }} \\
\hline \multirow{2}{*}{$\begin{array}{c}\text { Click } \\
\text { Intensity }\end{array}$} & \multirow{2}{*}{$\begin{array}{c}\text { Presentation } \\
\text { Mode }\end{array}$} & & & & & \\
\hline & & & & $<\mathbf{0}$ & $=\mathbf{0}$ & $>0$ \\
\hline Weak & $\underset{\mathbf{M e a n}}{\mathbf{S}_{\mathbf{R}} \mathbf{C}_{\mathbf{L}}}$ & $\begin{array}{l}-.95 \\
-.68 \\
-.82\end{array}$ & $\begin{array}{l}1.20 \\
1.35 \\
1.28\end{array}$ & $\begin{array}{l}69 \\
53 \\
61\end{array}$ & $\begin{array}{l}20 \\
22 \\
21\end{array}$ & $\begin{array}{l}11 \\
25 \\
18\end{array}$ \\
\hline Strong & $\begin{array}{c}\mathbf{S}_{\mathbf{R}} \mathbf{C}_{\mathbf{L}} \\
\mathbf{S}_{\mathbf{L}} \mathbf{C}_{\mathbf{R}} \\
\mathbf{M e a n}\end{array}$ & $\begin{array}{r}-.99 \\
-.59 \\
-.79\end{array}$ & $\begin{array}{l}1.15 \\
1.09 \\
1.12\end{array}$ & $\begin{array}{l}67 \\
54 \\
61\end{array}$ & $\begin{array}{l}25 \\
28 \\
26\end{array}$ & $\begin{array}{r}8 \\
18 \\
13\end{array}$ \\
\hline $\begin{array}{l}\text { Mean of Both } \\
\text { Intensities }\end{array}$ & $\begin{array}{l}\mathbf{S}_{\mathbf{R}} \mathbf{C}_{\mathbf{L}} \\
\mathbf{s}_{\mathbf{L}} \mathbf{C}_{\mathbf{R}}\end{array}$ & $\begin{array}{l}-.97 \\
-.64\end{array}$ & $\begin{array}{l}1.18 \\
1.22\end{array}$ & $\begin{array}{l}68 \\
\mathbf{5 3} \\
\end{array}$ & $\begin{array}{l}22 \\
\mathbf{2 5}\end{array}$ & $\begin{array}{r}9 \\
22 \\
\end{array}$ \\
\hline
\end{tabular}

*In one-syllable units. See text for description of scoring procedure.

+Negative means that the reported position precedes the actual position of the click.

is ambiguous from at least two points of view: (1) Material presented through an earphone to the left ear is felt as coming from a source in the left part of auditory space, and vice-versa for the right ear. The relevant factor in ear asymmetry might thus be the fact of reaching or not reaching a particular ear or the apparent location of the source in space. (2) The side on which it is presented might be critical for both the click and the speech or for only one of the two components. Other ear-asymmetry effects have been found to be specific of particular material, as in the well-known case of dichotic memory where speech received in the right ear is better recalled than speech received simultaneously in the left ear (Kimura, 1961), while the opposite is true of melodies (Kimura, 1964) and of emotional tone (Haggard \& Parkinson, 1971). In Experiment 1, the speech and the click changed sides simultaneously and the possible effects of these two changes were confounded.

The question of ear of entry vs position in auditory space can be answered by using binaural presentations. As is well known, a stimulus presented binaurally through earphones is felt as originating from a source in the middle of the head. Its apparent location is thus in between those of left and right monaural ones (hence it will be labeled as coming from the "middle" and the corresponding symbols will be $S_{M}$ and $C_{M}$ ). For such a stimulus, ear-of-entry and spatial-position interpretations give different predictions. There are, in fact, two different ear-of-entry interpretations which are consistent with the observed ear asymmetry. For one, which we shall call the left-ear precedence hypothesis, material reaching the left ear is perceived as coming earlier, relative to some constant reference stimulus, than similar material reaching only the right ear. A binaural stimulus obtains, then, the same precedence as a left monaural stimulus over a right monaural one.
Following the other version, called the right-ear-delay hypothesis, material reaching the right ear is perceived as coming later than similar material reaching only the left ear. A binaural stimulus is delayed to the same extent as a right monaural one, in comparison to a left monaural one. If it is position in auditory space that influences perceived order, a binaural stimulus will be perceived as coming later than a left monaural one, but earlier than a right monaural one.

Peculiarly convenient for testing the ear-of-entry hypotheses are the pairs of conditions $S_{M} C_{L}-S_{L} C_{M}$ and $S_{R} C_{M}-S_{M} C_{R}$. In the two conditions of the first pair, the click and the speech both reach the left ear; hence the left-ear-precedence hypothesis predicts the same mean error. On the other hand, since only the speech reaches the right ear in Condition $S_{M} C_{L}$ and only the click does in Condition $S_{L} C_{M}$, the right-ear-delay hypothesis predicts a smaller (or more negative) mean error in $S_{M} C_{L}$ than in $S_{L} C_{M}$. For the pair $S_{R} C_{M}-S_{M} C_{R}$, the opposite predictions are made: left-ear precedence predicts a smaller mean error in $S_{R} C_{M}$ than in $S_{M} C_{R}$, and right-ear-delay predicts no difference. To sum up: left-ear precedence predicts

$$
S_{M} C_{L}=S_{L} C_{M} \text { and } S_{R} C_{M}<S_{M} C_{R} ;
$$

right-ear-delay predicts

$$
S_{M} C_{L}<S_{L} C_{M} \text { and } S_{R} C_{M}=S_{M} C_{R}
$$

Finally, since in each pair the two conditions have the components in opposite relative positions, the spatial-position hypothesis predicts

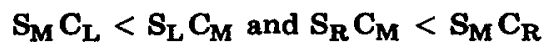

(symbols like $S_{M} C_{L}$ will be used 
Table 2

Results of Experiment 2

\begin{tabular}{|c|c|c|c|c|c|}
\hline \multirow[b]{2}{*}{ Condition } & \multirow{2}{*}{$\begin{array}{l}\text { Mean } \\
\text { Error }\end{array}$} & \multirow[b]{2}{*}{ SD } & \multicolumn{3}{|c|}{ Percent Errors } \\
\hline & & & $<0$ & $=0$ & $>0$ \\
\hline $\begin{array}{l}\mathbf{s}_{\mathbf{M}} \mathbf{C}_{\mathbf{L}} \\
\mathbf{s}_{\mathbf{M}} \mathbf{C}_{\mathbf{R}} \\
\mathbf{s}_{\mathbf{R}} \mathbf{C}_{\mathbf{M}} \\
\mathbf{s}_{\mathbf{L}} \mathbf{C}_{\mathbf{M}}\end{array}$ & $\begin{array}{r}-.86 \\
-.40 \\
-.87 \\
-.53\end{array}$ & $\begin{array}{l}1.21 \\
1.06 \\
1.06 \\
1.18\end{array}$ & $\begin{array}{l}63 \\
47 \\
66 \\
50\end{array}$ & $\begin{array}{l}24 \\
32 \\
26 \\
\mathbf{3 5}\end{array}$ & $\begin{array}{r}13 \\
21 \\
8 \\
15\end{array}$ \\
\hline
\end{tabular}

indifferently to denote a condition or the mean error under that condition).

Other pairs of conditions (such as $S_{R} C_{L}-S_{R} C_{M}$ or $S_{L} C_{L}-S_{M} C_{L}$ ) would also provide tests of ear-of-entry interpretations, but the present pairs had the interesting property, for a first examination, that each prediction holds whether laterality affects the perception of the sentence only, of the click only, or of both.

The question of specificity can be answered by two other comparisons involving the same four conditions. The predictions are straightforward here. If presentation mode matters only for speech, we have

$$
S_{R} C_{M}<S_{L} C_{M} \text { and } S_{M} C_{L}=S_{M} C_{R} \text {. }
$$

If it matters only for the click, we have

$$
S_{R} C_{M}=S_{L} C_{M} \text { and } S_{M} C_{L}<S_{M} C_{R} \text {. }
$$

If it matters for both,

$$
S_{R} C_{M}<S_{L} C_{M} \text { and } S_{M} C_{L}<S_{M} C_{R} \text {. }
$$

As it is possible that the effect would in some way be related to lateral dominance, only right-handed Ss were used in this and the following experiments. The results of $\mathrm{Ss}$ who either wrote with the left hand or declared being left-handed or ambidextrous, when questioned after the experiment, were discarded from the present analysis. No such precaution had been taken in Experiment 1.

\section{Method}

The responses of 32 inexperienced right-handed Ss will be analyzed. Each heard the four lists, one under each of the four conditions: binaural speech and click to the left ear $\left(S_{M} C_{L}\right)$ or the right ear $\left(S_{M} C_{R}\right)$, binaural click and speech to the left ear $\left(S_{L} C_{M}\right)$ or the right ear $\left(S_{R} C_{M}\right)$. Sixteen $S$ s started with the two conditions with binaural speech, and the other 16 with those with binaural click. Within each group, a subgroup of $8 \mathrm{Ss}$ had the monaural stimulation first left then right and the other subgroup in the opposite order. The order of the lists was organized in four different Latin squares. The level of the speech and of the click were left at the same intensity levels (click, 35 sones; speech peak level, about 35 sones) during binaural and monaural presentations. This means that the binaurally presented stimulation was felt to be louder than the monaurally presented one. Since no effect of click intensity had been found in Experiment 1, it seemed unnecessary to compensate for these differences.

\section{Results}

The mean errors appear in Table 2. Variance analysis revealed a condition effect significant at $p=.001 \quad(F=14.3$, $\mathrm{df}=\mathbf{3}, 93$ ). Subsequent application of Scheffé's test (Hays, 1963, p. 484) permitted the formation of two groups, one with Conditions $\mathrm{S}_{\mathrm{R}} \mathrm{C}_{M}$ and $S_{M} C_{L}$ and the other with Conditions $S_{L} C_{M}$ and $S_{M} C_{R}$, such that each condition of one group gives results significantly different at $\mathrm{p}=.05$ from each condition of the other group and no difference within a group is significant. In other words, each condition with the click originating from a location to the left of the speech produces a more negative mean displacement than each of the conditions with the click to the right of the speech. If proportions of the different response categories are considered instead of mean errors, the same general picture emerges.

\section{Discussion}

The two ambiguities described in the introduction have been eliminated. (1) The results are inconsistent with the predictions of the two ear-of-entry interpretations ( $1 \mathrm{a}$ and $1 \mathrm{~b})$, and they support those (1c) of the spatial-position hypothesis. (2) They support predictions (2c) derived from the hypothesis that the laterality of both the click and the speech affect perceived order.

If we combine both results, it appears that the relevant factor in lateral asymmetry is the relative apparent location of the sources of stimulation in auditory space.

As usual, the negative aspects of the conclusions, those regarding the interpretations that have been rejected, can be stated more firmly than the positive aspects. For specificity, we can say that the spatial position of each component can affect perceived order. The conclusion, however, rests on the particular cases where one component is shifted from the left to the right, while the other component is kept in the middle. One cannot affirm that, whatever the position of one component, moving the other one will affect perceived order.

Similarly, the support for a spatial-position interpretation comes from the sole consideration of what happens when the two components exchange positions between the middle and one side. This does not permit us to specify the relation between perceived order and spatial location in a detailed way. The simplest possible relation would be that the apparent time of occurrence of the click relative to the speech is progressively delayed when it is moved from the farthest position to the left of the speech to the farthest one to the right. But a difficulty for this simple hypothesis arises immediately from a comparison of the results of Experiments 1 and 2. Laterality produced an effect of similar magnitude (.33 and .39 syllables), despite the fact that left-right separation of the components was involved in Experiment 1 and only left-middle or middle-right in Experiment 2. There is thus a suggestion that, although perceived sequence depends on relative position of the components in acoustic space, it might not depend on the distance between them. The next experiment will be devoted to that problem.

\section{EXPERIMENT 3}

This experiment was run to compare the lateral asymmetry between conditions with full-head separation of the components and between conditions with half-head separation. Since there were four half-head separation conditions to consider, and only four lists of sentences were available, the comparison was made in two steps, on two separate groups of Ss.

\section{Method}

Two groups of 16 right-handed inexperienced Ss were tested. The Ss of Group 1 heard one list under each of Conditions $S_{M} C_{L}, S_{M} C_{R}, S_{R} C_{L}$, and $S_{L} C_{R}$ and those of Group 2 under Conditions $S_{R} C_{M}, S_{L} C_{M}, S_{R} C_{L}$, and $S_{L} C_{R}$. The order of presentation of the four conditions was organized in Latin squares.

\section{Results and Discussion}

The mean errors appear in Table 3 . In each group, the laterality effect due 
to full-head separation $\left(S_{L} C_{R}-S_{R} C_{L}\right)$ is larger than the one due to half-head seperation: .56 against .23 in Group 1 and .52 against .34 in Group 2. In each group, the corresponding planned comparison (Hays, 1963, p. 462ff) was performed as follows: Group 1, $\left(S_{L} C_{R}-S_{R} C_{L}\right)-\left(S_{M} C_{R}-S_{M} C_{L}\right)=$ $.33 ; \mathrm{t}=2.0$, df $=45 ; \mathrm{p}<.05 ;$ Group 2 , $\left(S_{L} C_{R}-S_{R} C_{L}\right)-\left(S_{L} C_{M}-S_{R} C_{M}\right)=$ $.19 ; t=1.36, \mathrm{df}=45 ; \mathrm{p}<.10$.

If one limited oneself to the question asked in the introduction, the conclusion would be that, despite the rather low significance levels, the results run counter to the suggestion derived from the two previous experiments: full-head separation produces a larger lateral asymmetry than does half-head separation. But Table 3 shows clearly that the difference is due wholly to the conditions where the click comes to the left of the speech: $S_{R} C_{L}$ produces a larger negative displacement than either $S_{M} C_{L}$ or $S_{R} C_{M}$ (the differences are .28 and .30 syllable, respectively). When the click comes to the right of the speech, only small and erratic differences are observed between $S_{L} C_{R}$ and either $S_{M} C_{R}$ or $S_{L} C_{M}(.05$ and -.11 syllable, respectively). These observations suggest strongly that amount of separation might influence apparent order when the click is to the left of the speech, not when it is to the right. The suggestion, which had not been anticipated, can, however, not be tested on the present data.

Proportions in the different response categories provide no further

\section{EXPERIMEN'T 4}

All the previous analyses have been based on differences between conditions with opposite lateralities: conditions with the click to the left of the speech have been compared to conditions with the click to the right of the speech. Control conditions without spatial separation have not been considered. Now that Experiment 3 has suggested that the effects of spatial separation might not be equally strong for all relative positions of the components, it becomes necessary to study the relation in a more detailed way. The

Table 4

Experiment 4: Mean Exrors and Standard Deviations

\begin{tabular}{|c|c|c|c|c|c|c|}
\hline \multirow[b]{2}{*}{$\begin{array}{r}\text { Degree of } \\
\text { Separation } \\
\end{array}$} & \multicolumn{3}{|c|}{ Group L } & \multicolumn{3}{|c|}{ Group R } \\
\hline & Condition & $\begin{array}{l}\text { Mean } \\
\text { Error }\end{array}$ & SD & Condition & $\begin{array}{l}\text { Mean } \\
\text { Error }\end{array}$ & SD \\
\hline Full-head & $\mathbf{s}_{\mathbf{R}} \mathbf{C}_{\mathbf{L}}$ & -.85 & 1.16 & $\mathbf{S}_{\mathbf{L}} \mathbf{C}_{\mathbf{R}}$ & -.49 & 1.08 \\
\hline Half-head & $\begin{array}{l}\mathbf{S}_{\mathbf{R}} \mathbf{C}_{\mathbf{M}} \\
\mathbf{S}_{\mathbf{M}} \mathbf{C}_{\mathbf{L}}\end{array}$ & $\begin{array}{l}-.65 \\
-.77\end{array}$ & $\begin{array}{l}1.15 \\
1.05\end{array}$ & $\begin{array}{l}\mathbf{S}_{\mathbf{L}} \mathbf{C}_{\mathbf{M}} \\
\mathbf{S}_{\mathbf{M}} \mathbf{C}_{\mathbf{R}}\end{array}$ & $\begin{array}{r}-.48 \\
-.49\end{array}$ & $\begin{array}{l}1.15 \\
1.22\end{array}$ \\
\hline No Separation & $\mathbf{S}_{\mathbf{M}} \mathbf{C}_{\mathbf{M}}$ & -.54 & 1.05 & $\mathbf{s}_{\mathbf{M}} \mathbf{C}_{\mathbf{M}}$ & -.58 & 1.19 \\
\hline
\end{tabular}
information and have been omitted.

present experiment was performed to compare (1) conditions with full-head separations with conditions with half-head separation, and (2) conditions with half-head separation with a control condition without separation, with separate comparisons being run for the cases where the click is to the left of the speech and where the click is to the right of the speech. For the sake of homogeneity, the experiment was run with the same set of four sentences as the former ones, which involved using two separate groups of Ss and limiting oneself to one only of the three possible control conditions. The one with both components presented binaurally was chosen.

\section{Method}

Two groups of 24 inexperienced right-handed Ss were tested. Each S heard the four lists, one under each of four presentation modes. The Ss of Group $L$ had Conditions $\mathbf{S}_{\mathbf{R}} \mathbf{C}_{L}$, $S_{R} C_{M}, S_{M} C_{L}$, and $S_{M} C_{M}$. Those of Group $R$ had Conditions $S_{L} C_{R}$, $S_{L} C_{M}, S_{M} C_{R}$, and $S_{M} C_{M}$. For each group, the order of the conditions was organized using six Latin squares. The four lists were always presented in the same order.

\section{Results and Discussion}

The mean errors are given in Table 4. In Group L, the negative displacement increases with increasing separation of the components. Variance analysis revealed a significant effect of conditions ( $F=4.8$, df $=3,69 ; p<.01$ ). The differences were further analyzed through planned comparisons: (1) The mean error over Conditions $S_{M} C_{L}$ and $S_{R} C_{M}$ was found to be significantly more

Table 3

Experiment 3: Mean Errors and Standard Deviations

\begin{tabular}{|c|c|c|c|c|c|c|}
\hline \multirow[b]{2}{*}{$\begin{array}{l}\text { Degree of } \\
\text { Separation }\end{array}$} & \multicolumn{3}{|c|}{ Group 1} & \multicolumn{3}{|c|}{ Group 2} \\
\hline & Condition & $\begin{array}{l}\text { Mean } \\
\text { Error }\end{array}$ & SD & Condition & $\begin{array}{l}\text { Mean } \\
\text { Error }\end{array}$ & SD \\
\hline Full-head & $\begin{array}{l}\mathbf{S}_{\mathbf{R}} \mathbf{C}_{\mathbf{L}} \\
\mathbf{S}_{\mathbf{L}} \mathbf{C}_{\mathbf{R}}\end{array}$ & $\begin{array}{r}-1.07 \\
-.51\end{array}$ & $\begin{array}{l}1.23 \\
1.16\end{array}$ & $\begin{array}{l}\mathbf{S}_{\mathbf{R}} \mathbf{C}_{\mathbf{L}} \\
\mathbf{s}_{\mathbf{L}} \mathbf{C}_{\mathbf{R}}\end{array}$ & $\begin{array}{r}-1.19 \\
-.67\end{array}$ & $\begin{array}{l}1.24 \\
1.10\end{array}$ \\
\hline Half-head & $\begin{array}{l}\mathbf{S}_{\mathbf{M}} \mathbf{C}_{\mathbf{L}} \\
\mathbf{S}_{\mathbf{M}} \mathbf{C}_{\mathbf{R}}\end{array}$ & $\begin{array}{r}-.79 \\
-.56\end{array}$ & $\begin{array}{l}1.12 \\
1.23\end{array}$ & $\begin{array}{l}\mathbf{S}_{\mathbf{R}} \mathbf{C}_{\mathbf{M}} \\
\mathbf{s}_{\mathbf{L}} \mathbf{C}_{\mathbf{M}}\end{array}$ & $\begin{array}{r}-.90 \\
-.56\end{array}$ & $\begin{array}{l}1.07 \\
1.10\end{array}$ \\
\hline
\end{tabular}

negative than the mean for Control Condition $S_{M} C_{M} \quad(t=2.07, d f=69$; $p<.025$ ). (2) Tested in the same way, the difference between Condition $S_{R} C_{L}$ and the mean of $S_{M} C_{L}$ and $S_{R} C_{M}$ fell just short of the .05 level ( $t$ $=1.63 ; t_{.05}=1.67$ ). (3) The difference between $S_{M} C_{L}$ and $S_{R} C_{M}$, for which there was no prediction, was submitted to a two-tailed test and found to be nonsignificant $(t=1.17$; $t_{.10}=1.67$ ).

In Group $R$, the control condition, $\mathbf{S}_{\mathbf{M}} \mathbf{C}_{\mathbf{M}}$, produces a slightly more negative mean error than the three other conditions, which give practically identical results. Variance analysis yielded a nonsignificant effect of conditions $(F<1)$. Planned comparisons, run according to the same principle as in Group $L$, gave no significant outcome: the only noticeable difference, that between $S_{M} C_{M}$ and the mean of $S_{M} C_{R}$ and $S_{L} C_{M}$, did not reach the .10 level.

This picture of the relation between apparent order and spatial separation is in agreement with the suggestion brought forth by Experiment 3. Conditions where the click is to the left of the speech give larger negative displacements than does the control condition with both components in the middle. Among these conditions, the negative displacement seems to increase with increasing spatial separation of the components. On the other hand, for the conditions where the click comes to the right of the speech, degree of separation seems to make no difference and the negative displacement is not, or is only slightly, smaller than in the control condition.

The affirmation that an effect of degree of separation was shown in Group L might be criticized, not so much in view of the low significance level at which the null hypothesis was rejected, but mainly because it involves considering as meaningful the .08 syllable difference between Conditions $S_{M} C_{L}$ and $S_{R} C_{L}$, while the larger difference (.12 syllable) between $S_{M} C_{L}$ and $S_{R} C_{M}$ is discarded as nonsignificant. The conclusion was made possible by the pooling of the latter two conditions. There was good justification for pooling: the two conditions had yielded virtually identical results in Experiment 2. But 
even if based on sound statistical procedure, the result is counterintuitive. For that reason, it may be worth mentioning that in a preliminary experiment where $16 \mathrm{Ss}$ were run under exactly the same conditions as Group L (but with a less satisfactory control of list effects-the reason why the data were not included in the analysis), the mean errors for Conditions $S_{M} C_{L}$ and $S_{R} C_{M}$ were, respectively, -.55 and -.70 syllable. The difference was thus in the opposite direction to the one observed in Group L, and, in fact, the two conditions give exactly the same mean (-.67) when the results of the two groups of Ss are pooled.

The fact that perceived order is not influenced by separation when the click is to the right of the sentence does not discard the previous conclusion that the relevant factor in lateral asymmetry is relative position of the components. As was noted in the discussion of Experiment 2, the conclusion was compatible with several relations between perceived sequence and spatial position. Experiments 3 and 4 have now shown that the relation is more complex than a simple constantly increasing one. To help visualizing the relation, the mean errors per condition have been calculated over all the responses collected in all four experiments and are shown in Fig. 1. Such data, where different groups of Ss have contributed to different but partially overlapping sets of means, could not be submitted to statistical tests; but in view of the rather high variability of the data, it was felt worthwhile to present estimates based on the largest available samples. The pattern which emerges is rather clear.

In Experiment 2, rejection of the two ear-of-entry interpretations was based on the respective findings that $S_{L} C_{M}<S_{M} C_{L}$ and $S_{R} C_{M}<S_{M} C_{R}$. It was mentioned in the discussion that other comparisons could have been used to the same purpose, and some of them have now become available. Each ear-of-entry hypothesis predicts one particular ordering of the mean errors under the seven conditions which have been used, and these orderings can be compared with the data appearing in Fig. 1 . The left-ear-precedence hypothesis predicts $\mathbf{S}_{\mathbf{R}} \mathbf{C}_{\mathrm{L}}=\mathbf{S}_{\mathbf{R}} \mathbf{C}_{\mathbf{M}}<\mathbf{S}_{\mathbf{M}} \mathbf{C}_{\mathrm{L}}=\mathbf{S}_{\mathbf{M}} \mathbf{C}_{\mathbf{M}}=$ $\mathbf{S}_{\mathbf{L}} \mathbf{C}_{\mathbf{M}}<\mathbf{S}_{\mathbf{M}} \mathbf{C}_{\mathbf{R}}=\mathbf{S}_{\mathbf{L}} \mathbf{C}_{\mathbf{R}}$ and the right-ear-delay hypothesis predicts $\mathbf{S}_{\mathbf{R}} \mathbf{C}_{\mathbf{L}}=\mathbf{S}_{\mathbf{M}} \mathbf{C}_{\mathbf{L}}<\mathbf{S}_{\mathbf{R}} \mathbf{C}_{\mathbf{M}}=\mathbf{S}_{\mathbf{M}} \mathbf{C}_{\mathbf{M}}=$ $S_{M} C_{R}<S_{L} C_{M}=S_{L} C_{R}$. Each of these predictions contains numerous discrepancies with the data.

The omission of Control Conditions $S_{L} C_{L}$ and $S_{R} C_{R}$, which might appear as a weak point in our evidence, is of no consequence regarding the rejection

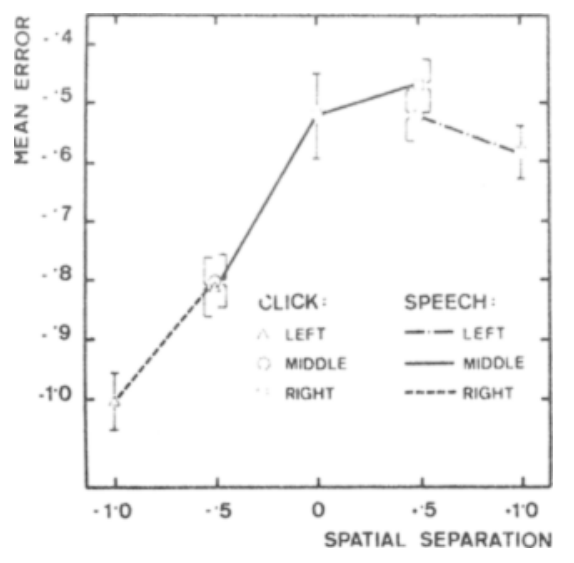

Fig. 1. Mean error per condition as a function of spatial separation between click and speech. All responses collected during the four experiments have been pooled (for Experiments 2, 3 , and 4, right-handed Ss only). Each point is based on 480 responses for Condition $S_{M} C_{M}, 880$ for Conditions $S_{R} C_{L}$ and $S_{L} C_{R}$, and 720 for all other conditions. Separation is negative when the click is to the left of the speech: -1 and +1 correspond to left-right separation, -.5 and +.5 to left-middle or middle-right separation. Brackets indicate \pm 1 standard error intervals.

of ear-of-entry interpretations, for both share with spatial-position interpretations the prediction that: $S_{L} C_{L}=S_{M} C_{M}=S_{R} C_{R}$.

\section{GENNERAL DISCUSSION}

Apart from confirming the existence of an ear-asymmetry effect in the click location task, our experiments have brought several precisions regarding the origin of the phenomenon. It now appears as one particular manifestation of a more general relation between perceived sequence and the relative positions in auditory space of the apparent sources of the speech and of the click. The relation, however, is not a simple one: perceived order is influenced by spatial separation only when the click is to the left of the speech.

The expression "relative positions in auditory space of the apparent sources" should be read keeping in mind that only one way of creating an impression of spatial location, namely, manipulating the distribution of the components between the two earphones, has been used throughout. Other ways should be tried before the conclusion can be generalized. One should, for instance, have the speech and the click delivered through loudspeakers with different angular separations. A comparison of the present results with those of a previous study using the same material presented through two loudspeakers (Bertelson \& Tisseyre, 1970) suggests that the two situations do not necessarily yield identical results. In the former study, where there was no separation between the loudspeakers, the mean error was about -1 syllable, which is about twice the negative displacement observed in Experiment 4 under the control condition without separation and of the same order of magnitude as in Condition $S_{R} C_{L}$. The measures are not strictly comparable, in view of the differences in instructions between the two studies, but it would be surprising if these differences could by themselves produce such large shifts in mean errors.

The relation of the present phenomenon to other perceptual asymmetries is far from clear. This is especially the case of the ear asymmetry observed in dichotic speech recognition (Kimura, 1961, 1966; Bryden, 1963). Kimura's interpretation of that phenomenon in terms of localization of the speech center and occlusion of ipsilateral speech messages by contralateral ones would have difficulties explaining an effect linked to spatial position, not to ear of entry. Kinsbourne's (1970) more sophisticated idea of a relation between central dominance and the spatial distribution of attention would avoid that difficulty but would presumably predict some precedence of material presented to the right. Irrespective of the particular explanation which is considered, it is doubtful whether a single mechanism might explain both right-ear advantage in dichotic speech recognition and precedence of a click presented to the left of the speech in the click location task.

Regarding the possibility of a relation to cerebral dominance, the pooled results of the $18 \mathrm{Ss}$ whose results have been discarded from the main analysis in Experiments 2, 3, and 4 because they wrote with the left hand or reported left-handed or ambidextrous habits have been presented in Table 5. Their mean errors are on the whole slightly less negative than those of the right-handed $\mathrm{Ss}$, but the differences between conditions display a lateral asymmetry of same size and direction. The observation offers no support to the notion of some relation to cerebral dominance but is, of course, not sufficient to discard it: handedness is a rather poor predictor of cerebral dominance (Kimura, 1966), and our way of assessing it was obviously not optimal.

Another possible relation which might be worth exploring is to cultural stereotypes linked with the direction 
Table 5

Exporiments 2, 3, and 4: Mean Errors of Left-Handed and Ambldextrous Ss Compared to Those of Risht-Handed Ss

\begin{tabular}{|c|c|c|c|c|}
\hline \multirow[b]{2}{*}{ Conditions } & \multicolumn{2}{|c|}{ Right-Handed } & \multicolumn{2}{|c|}{$\begin{array}{c}\text { Left-Handed and } \\
\text { Ambidextrous* }\end{array}$} \\
\hline & $\mathbf{N t}$ & $\begin{array}{l}\text { Mean } \\
\text { Error }\end{array}$ & $\mathbf{N}+$ & $\begin{array}{l}\text { Mean } \\
\text { Error }\end{array}$ \\
\hline $\mathbf{S}_{\mathbf{R}} \mathbf{C}_{\mathbf{L}}$ & 560 & -1.01 & 80 & -.80 \\
\hline $\mathbf{s}_{\mathbf{R}} \mathbf{C}_{\mathbf{M}}, \mathbf{s}_{\mathbf{M}} \mathbf{C}_{\mathbf{L}}$ & 1440 & -.81 & 220 & -.56 \\
\hline $\begin{array}{l}\mathbf{S}_{\mathbf{M}} \mathbf{C}_{\mathbf{M}}, \mathbf{s}_{\mathbf{L}} \mathbf{C}_{\mathbf{M}} \\
\mathbf{s}_{\mathbf{M}} \mathbf{C}_{\mathbf{R}}, \mathbf{s}_{\mathbf{L}} \mathbf{C}_{\mathbf{R}}\end{array}$ & 2480 & -.52 & 420 &.- .31 \\
\hline
\end{tabular}

*Experiment 2-six Ss; Experiment 3, Group 1-three Ss, Group 2-one S; Experiment 4, Group $L$-four Ss, Group $R$-five $S s$

†Number of responses

of reading. Time runs from left to right on most graphical representations, and people often make a gesture to the left or to the right when saying "before" or "after."2 A companion paper is devoted to that problem.

In the authors' opinion, it is too early to speculate on the nature of the mechanism which might produce the effect. The only conclusion that can be stated firmly for the moment is that, at some stage of speech processing, temporal sequence must be represented in a code which is influenced by spatial position. No suggestion can yet be offered regarding the reason why the influence is felt only when the click is to the left of the speech.

Before more detailed interpretations can be attempted, more information is needed on the possibility of laterality effects in other situations involving judgments of temporal order. Very few data are available. Efron (1963) has examined the effect of spatial separation on judgments of temporal order in pairs of visual flashes and of cutaneous shocks. He found a very small ( $\pm 6 \mathrm{msec}$ ) precedence of stimuli presented on the right side: The effect is thus in the opposite direction to the one studied here and of much smaller magnitude: at the mean rate of 7 syllables/sec, the mean value of the laterality effect between $S_{R} C_{L}$ and $S_{M} C_{M}$ observed in Fig. 1 represents about $70 \mathrm{msec}$. In our laboratory, Bauwens (1970) has studied the effect of spatial separation of the sources on the perceived temporal order of a click and a flash. In one condition, the flash came always from a centrally located tube and the click from one of three loudspeakers situated to the left, in the middle, or to the right. In the other condition, the click always came in the middle and the flash in the middle or on one side. In no condition was any effect of spatial position apparent. It is tempting to hypothesize that one of the components submitted to the judgment of order must be a temporally organized pattern for lateral asymmetry to occur. Important in this respect is the preliminary result mentioned by Bever (1971), that ear asymmetry is not observed when the speech component consists of random word lists.

A problem without direct relevance to lateral asymmetry concerns the general direction of the errors. Under all conditions, a clear majority of prepositions has been observed. Even in the four conditions where the tendency is less pronounced, those where the click was not to the left of the sentence $\left(S_{M} C_{M}, S_{M} C_{R}, S_{L} C_{M}\right.$, and $S_{L} C_{R}$ ), negative responses represent $52 \%$ of all responses, $73 \%$ of all errors. The tendency emerges from the important variations which are observed between sentences. 3 In Conditions $S_{M} C_{R}$ and $S_{L} C_{M}$ of Experiment 2, for instance, where mean error per sentence ranges from -3.20 to +.75 syllables, 34 sentences out of 40 produce a negative mean error. A similar tendency to prepose an extraneous signal superimposed on an unknown string of speech has been reported by Ladefoged and Broadbent and by Bertelson and Tisseyre (1970) Bever, Lackner, and Kirk (1969), or Bever, Lackner, and Stolz (1969). (There was a small overall tendency towards positive errors in the last study and a negligibly small one towards negative errors in the other two.) Since the two studies mentioned first were conducted with diotic presentations in open space and the last three with dichotic presentations, one could wonder if that difference in presentation procedure was not at the origin of the discrepancy. The present results seem to rule out that possibility. There is for the time being no convincing explanation for the discrepancy. More recently, sizable negative displacements have been observed in an experiment by Warren and Obusek (1971), using a slightly different situation and only one position of the extraneous signal in one single sentence, and also in an experiment by Bever (1971, p. 236), but not by Fodor and Bever (1965), using monaural presentations (Conditions $S_{L} C_{L}$ and $S_{R} C_{R}$ ). In experiments reported recently by Reber and Anderson (1970), which are remarkable for a careful control of click positions, a majority of negative errors was observed early in the sesaion and gave way progressively to positive ones, so that no tendency prevailed over the whole session. Examination of the procedure suggests, however, that in both experiments the Ss had the possibility to gain knowledge about several syntactic and semantic features of the material, and it has been shown (Bertelson \& Tisseyre, 1970; Warren \& Obusek, 1971) that prior knowledge can eliminate negative displacements.

\section{REFERENCES}

BAUWENS, M. Entrée prioritaire et jugement d'ordre temporel. Unpublished thesis, University of Brussels, 1970.

BERTELSON, P., \& TISEYRE, F. Perceiving the sequence of speech and non-speech stimuli. The Quarterly Journal of Experimental Psychology, $1970,22,653-662$.

BEVER, T. G. The nature of cerebral dominance in speech behaviour of the child and aduit. In $R$. Huxley and $E$. Ingram (Eds.), Language acquisition: Models and methods, London: Academic Press, 1971. Pp. 231-254.

BEVER, T. G., KIRK, R., \& LACKNER, J. An autonomic reflection of syntactic structure. Neuropsychologia, 1969, 7, 23-28.

BEVER, T. G. LACKNER, J., \& KIRK, R. The underlying structure of sentences are the primary units of immediate speech processing. Perception \& Psychophysics, $1969,5,225-234$.

BEVER, T. G., LACKNER, J., \& STOLZ, W. Transitional probability is not a general mechanism for the segmentation of speech. Journal of Experimental Psychology, 1969, 70, 387-394.

BRYDEN, M. P. Ear preference in auditory perception. Journal of Experimental perception. Journal of Exper

EFRON, R. The effect of handedness on the perception of simultaneity and temporal order. Brain, 1963, 86, 261-284.

FODOR, J., \& BEVER, T. G. The psychological reality of linguistic segments. Journal of Verbal Learning \& Verbal Behavior, 1965, 4, 414-420.

HAGGARD, M. P., \& PARKINSON, A. $M$. Stimulus and task factors as determinants of ear advantages. The Quarterly Journal of Experimental Psychology, 1971, 23, 168-177.

HAYS, W. Statistics. New York: Holt, Rinehart \& Winston, 1963.

KIMURA, D. Cerebral dominance and the perception of verbal stimuli. Canadian Journal of Psychology, 1961, 15, 166-171.

KIMURA, D. Left-right differences in the perception of melodies. The Quarterly Joumal of Experimental Psychology, $1964,16,355-356$.

KIMURA, D. Functional asymmetry of the brain in dichotic listening. Cortex, 1966, 3, 163-178.

KINSBOURNE, $M$. The cerebral basis of latexal asymmetries in attention. In $A$. F. Sanders (Dd.), Attention and performance, III. Amsterdam: North-Holland, 1970. Pp. 193-201.

LADEFOGED, P., \& BROADBENT, D. E. Perception of sequence in auditory events. The Quarterly Journal of Experimental Psychology, 1960, 12, 162-170. 
LANDERCY, A. Etude et réalisation d'une clé vocale. Bruxelles: Rapport d'activités de l'Institut de Phonétique, 1969, 2, 115-120.

REBER, A. S.. \& ANDERSON, J. R. The perception of clicks in linguistic and nonlinguistic messages. Perception \& Psychophysics, 1970, 8, 81-89.

WARREN, R. M.. \& OBUSEK, C. J. Speech perception and phonemic restorations. Perception \& Psychophysics, 1971, 9 358-362.

WHITE, M. J. Laterality differences in perception. Psychological Bulletin, 1969, 72, 387-405.

NOTES

1. Since this paper was written, Bever
(1971) has discussed the relationship of the ear-asymmetry phenomenon to cerebral dominance and given a preliminary description of some experiments specifically designed to analyze it.

2. We are indebted to $P$. A. Osterrieth for this observation.

3. It has been suggested that the prevalence of negative errors might result from a combination of (1) the fact that in our material the mean location of the clicks was latex (.4 syllable) than the middle of the sentence, and (2) a negative correlation between mean error and position of the click in the sentence, as reported by Ladefoged and Broadbent (1960) and by Reber and Anderson (1970). The slight asymmetry in the distribution of click positions may have led to a small overestimation of the negative displacement but cannot be responsible for the whole effect. In Experiment 2, for instance, there was a -.22 product-moment correlation between mean error per sentence and distance of the click from the middle of the sentence, which means that moving the mean click position exactly to the middle might increase the mean error by about 0.02 syllable.

(Accepted for publication December 8, 1971.) 